\title{
Mechanisms of mindfulness for professional golfers: the mediating role of basic psychological needs
}

\author{
Hsin-Yun Chuang ${ }^{1} \cdot$ Fong-Jia Wang ${ }^{2} \cdot$ Li-Kang Chi $^{1}$ \\ Accepted: 18 May 2021 / Published online: 26 May 2021 \\ (C) The Author(s), under exclusive licence to Springer Science+Business Media, LLC, part of Springer Nature 2021
}

\begin{abstract}
The relationship between mindfulness and well-being and ill-being has been demonstrated to a great extent. In sports, the fulfillment of individuals' basic psychological needs depends mostly on support from others, such as that from a coach in a sports team context. However, a possible way for individuals to fulfill their basic psychological needs is by enhancing mindfulness rather than depending on others. Therefore, building on SDT and mindfulness, this study examines the mediating effect of basic psychological needs on mindfulness to predict subjective vitality and athlete burnout in professional golfers. The participants were 120 golfers (47\% females), with a mean age and golf experience of 22.28 and 9.48 years, respectively. The association between mindfulness and subjective vitality was partially mediated by the need for autonomy and relatedness. By contrast, the association between mindfulness and burnout was partially mediated by the need for competence and relatedness, thus supporting our mediation analysis. Overall, the study highlights mindfulness as a potential mechanism to ensure the fulfillment of basic psychological needs in golf training, which could enhance golfers' subjective vitality and reduce the occurrence of burnout.
\end{abstract}

Keywords Bootstrapping $\cdot$ Basic psychological needs theory $\cdot$ Mindfulness $\cdot$ Professional golf

\section{Introduction}

Ever since "positive psychology" was selected as the theme of the American Psychology Association in 1998, the research topic of well-being has gradually been becoming more popular (Ryan \& Deci, 2000, 2001; Ryff et al., 2004; Bahrami \& Cranney, 2018; Tanhan, 2019; Prime et al., 2020; Shankland et al., 2021). In the field of sports science, more studies have focused not only on sports performance, but also on athletes' well-being and ill-being, reflecting the positive psychology approach. Fraser-Thomas et al. (2008) reported that the psychological indicators of well-being and ill-being relate to the healthy and prolonged participation of athletes in sports. Additionally, Adie et al. (2010) recommended that subjective vitality and burnout could be indicators of well-being and ill-being.

Li-Kang Chi

likang.chi@gmail.com

1 Department of Physical Education, National Taiwan Normal University, No. 162, Section 1, Heping E. Rd., Taipei City 106, Taiwan

2 Office of Physical Education, Tamkang University, No.151, Yingzhuan Rd., New Taipei City 251301, Taiwan
Therefore, subjective vitality has become an important and dynamic indicator of well-being when exploring the psychological process behind individuals' motives. Subjective vitality is defined as a feeling of energy and aliveness, and represents an inner force facilitating mental and somatic health and has indicated that higher subjective vitality is associated with optimal psychological and emotional functioning (Ryan and Frederick 1997). In contrast, burnout is an exhaustive physiological and psychological reaction (Adie et al., 2010; Adie et al., 2012).

Humans have three basic psychological needs, namely, the innate needs for autonomy, competence, and relatedness, which are essential for positive human growth and optimal functioning (Ryan \& Deci, 2000). SDT suggests that when the three basic psychological needs (i.e., autonomy, competence, and relatedness) are fulfilled, effective functioning and well-being result (Deci and Ryan 2000). The satisfaction of all three of these components may enhance an individual's wellbeing, whereas a lack of fulfillment may cause an individual's ill-being to increase (Deci and Ryan 2000). By examining athletes' experiences, both their subjective vitality and burnout may be predicted. Furthermore, these basic psychological needs are important mediators between autonomy support and subjective vitality (Adie et al., 2008). The psychological needs fulfillment of individuals' depends mostly on support from 
others, such as the support from the coach of a sports team (Adie et al., 2008, 2012). Previous research by Adie et al. (2008) and Mack et al. (2011) indicated that basic psychological needs may positively predict subjective vitality. However, in one study, autonomy and competence were described as partial mediators between autonomy support and subjective vitality (Adie et al., 2008), while competence and relatedness were the mediators in a second study (Mack et al., 2011). When investigating sports burnout, one study found that elite rugby players' competence and autonomy were strong negative predictors of burnout, while relatedness could moderately and negatively predict burnout (Hodge et al., 2008). Conversely, research on high school student athletes found that three basic psychological needs can predict burnout, with low satisfaction of relatedness acting as the predominant predictor (Perreault et al., 2007). Lonsdale et al. (2009) found that autonomy and competence were significant negative predictors of athlete burnout. Summarizing these previous studies, the autonomy, competence, and relatedness of athletes can positively predict subjective vitality (Adie et al., 2008; Mack et al., 2011) and negatively predict athlete burnout (Hodge et al., 2008; Perreault et al., 2007).

Mindfulness is an important psychological characteristic that facilitates one's awareness of current thoughts, emotions, and bodily sensations with a non-judgmental attitude (Kabat-Zinn, 2003). Recent studies in sports have found that the mindfulness of National Collegiate Athletic Association (NCAA) Division I men's basketball players significantly predicted their game free throw percentages (Gooding \& Gardner, 2009). Mindfulness has been correlated with improved athletic performance and flow state (Cathcart et al., 2014; Scott-Hamilton et al., 2016). In the context of golf competitions, the higher the golfers' attentional control of mindfulness, the better the golfers' putting performance (Chuang \& Chi, 2017). In brief, mindfulness improves athletes' mental state and performance. However, a study by Chang et al. (2015) also suggested that enhancing mindfulness, rather than depending on others, was a possible way for individuals to fulfill basic psychological needs.

During COVID-19, recent research has shown that mindfulness has been one of the most important facilitators for individuals' mental health (Götmann \& Bechtoldt, 2021; Kanekar \& Sharma, 2020; Tanhan, 2020). According to previous research on mindfulness and well-being, individuals with higher mindfulness scores are more resistant to stress and better able to cope with stressful events due to their heightened awareness of the present reality and the attention they give to living in the moment (Roche et al., 2014). McCracken and Yang (2008) found that mindfulness was negatively correlated with stress and burnout, but was positively correlated with vitality, social functioning, and emotional functioning. Mindfulness has also been found to be beneficial for reducing burnout and stress in clinical trials (Weinstein \& Ryan, 2011). In a study of managers and entrepreneurs, Roche et al. (2014) found that mindfulness was negatively correlated with aspects of will-being, including anxiety, depression, and burnout. Anxiety, depression, and negative affect are widely recognized as relevant issues that impact organizational leaders' well-being, and a large amount of popular literature has been published around the precautions and steps that should be taken to prevent burnout (Roche et al., 2014). Within the field of sports, only a few studies have examined the relationship between mindfulness and burnout, and thus, further research is required. To summarize, the structure of mindfulness is still unclear, and studies examining the mediating role of basic psychological needs in the association between mindfulness and subjective vitality and athlete burnout is still limited.

This research tested the relations between variables with a sample of golfers using the theoretical model. Brown and Ryan (2003) found that mindfulness was positively related to subjective vitality. Thus, mindfulness is recognized as a phenomenon that affects a diverse range of factors, such as physical health, psychological well-being, sports performance, and the relationship between these factors (Brown \& Ryan, 2004). In terms of sports, mindfulness is an important aspect of golf. Golfers are prone to burnout if they train extremely hard without obvious improvement. A Taiwanese professional golfer (Yani Tseng), who had been World No. 1 for 109 consecutive weeks, won 12 events worldwide in 2011, which shows how much emphasis is placed on golf in Taiwan. Therefore, we hypothesized that an understanding of athletes' well-being and ill-being would help provide ways for the athletes continue to participate in their sport. The large diversity of well-being constructs associated with mindfulness suggests a number of social, personality, and health research avenues that could be explored to understand the impacts on psychological well-being (Brown \& Ryan, 2003). Despite the significance of these avenues for the mindfulness of athletes, these fields remain largely underexplored in the literature (Brown \& Ryan, 2003; Chang et al., 2018). Hence, the current study is the first to evaluate mindfulness from a professional golfer's perspective.

Consistent with the literature reviewed above, we formulated two specific hypotheses. First, we predicted that three basic psychological needs would mediate the relationships between mindfulness and subjective vitality, and second, that three basic psychological needs would mediate the relationships between mindfulness and athlete burnout. Therefore, based on SDT (Ryan \& Deci, 2000), the purpose of this study was to examine the mediating effect of basic psychological needs on mindfulness in predicting subjective vitality and athlete burnout.

\section{Methods}

\section{Participants}

A total of 150 questionnaires were administered, with an effective return ratio of $80 \%$. In total, 120 Taiwanese golfers (64 
males and 56 females) participated, with an average age of $22.28(S D=6.86)$ and an average of $9.48(S D=6.70)$ years of golf experience were recruited from Taiwan. The average training frequency of the golfers was 5.23 times per week, with an average duration of $4.63 \mathrm{~h}$. Researchers explained the purpose of the research and informed the participants of their ethical rights in person before they provided their consent. In the confirmatory factor analysis (CFA), we confirmed the factor structure of model, through evaluating the factor loading of each of the items, the values of composite reliability (CR) and the average variance extracted (AVE) of the factors (Bagozzi \& $\mathrm{Yi}, 1988$ ). Moreover, CFA was performed to cross-validate and confirm the factors structure derived in the analysis. The goodness-of-fittest on the model was assessed using chi-square, root mean square error of approximation (RMSEA; < 0.08), comparative fit index (CFI; $>0.90$ ), standardized root mean square residual (SRMR; < .05), goodness of fit index (GFI; > 0.80 ), incremental fit index (IFI; > 0.80), and normal fit index (NFI; > 0.80) (Hu \& Bentler, 1999).

\section{Measures}

The Five Facet Mindfulness Questionnaire The 39-item Five Facet Mindfulness Questionnaire (FFMQ) developed by Baer et al. (2006) assesses five facets of general mindfulness tendencies in daily life: observing, describing, acting with awareness, not reacting to inner experiences, and not judging inner experiences. Items are rated on a five-point Likert-type scale ranging from 1 (never or very rarely true) to 5 (very often or always true). An example of a question on this scale is: "When I do things, my mind wanders off and I'm easily distracted". This questionnaire has a good internal consistency (Cronbach's $\alpha=$ $0.74-0.88$ ). Then, a confirmatory factor analysis (CFA) was conducted to examine the fit and the criteria for the item selection of the measurement (Hu \& Bentler, 1999). The CFA showed that all model fit statistics were all adequate, as follows: chi-square $(\chi 2 / d f=2.225, p<.001), \mathrm{GFI}=0.64$, RMSEA $=$ $0.10, \mathrm{SRMR}=0.13, \mathrm{CFI}=0.71, \mathrm{IFI}=0.69, \mathrm{NFI}=0.72$, and all models have satisfactory values on fit indices. The factor loading of all items ranged from 0.47 to 0.86 , and all composite reliability ranged from 0.82 to 0.89 , suggesting that the observed variables sufficiently represented the latent variables.

Subjective Vitality Scale The seven-item Subjective Vitality Scale (Ryan and Frederick 1997) was used to measure subjective vitality. The items were answered using a seven-point scale, ranging from 1 (not at all true) to 7 (very true). An example of a question on this scale is: "I feel alive and vital". This scale has a high reliability (Cronbach's $\alpha=0.85$ ).

Athlete Burnout Questionnaire The 11-item Athlete Burnout Questionnaire (Raedeke \& Smith, 2001) was used to measure athlete burnout. This questionnaire includes three subscales:
1) emotional/physical exhaustion; 2) devaluation; and 3) reduced sense of accomplishment. Items are rated on a 5-point Likert-type scale ranging from 1 (never or very rarely true) to 5 (very often or always true). An example of a question on this scale is: "I feel overly tired from exercise in general and other sports". The questionnaire had good internal consistency (Cronbach's $\alpha=0.70-0.88$ ). Then, a CFA was conducted to examine the fit and the criteria for the item selection of the measurement (Hu \& Bentler, 1999). The CFA showed that all model fit statistics were all adequate, as follows: chi-square $(\chi 2 / d f=2.451, p<.001), \mathrm{GFI}=0.86, \mathrm{RMSEA}=0.11$, $\mathrm{SRMR}=0.07, \mathrm{CFI}=0.94, \mathrm{IFI}=0.94, \mathrm{NFI}=0.92$, and all models have satisfactory values on fit indices. The factor loading of all items ranged from 0.46 to 0.93 , and all composite reliability ranged from 0.63 to 0.92 , suggesting that the observed variables sufficiently represented the latent variables.

Basic Need Satisfaction Scale The 10-item Basic Need Satisfaction Scale (Deci et al. 2001) was used to assess the degree to which the basic psychological needs of the golfer were met. This scale included three subscales: 1) autonomy; 2) competence; and 3) relatedness. The items were answered using a seven-point scale, ranging from 1 (not at all true) to 7 (very true). An example of a question in this scale is: "I feel like I can pretty much be myself at work". The scale provided has good internal consistency (Cronbach's $\alpha=0.75-0.81$ ). Then, a CFA was conducted to examine the fit and the criteria for the item selection of the measurement (Hu \& Bentler, 1999). The CFA showed that all model fit statistics were all adequate, as follows: chi-square $(\chi 2 / d f=1.869, p<.001), \mathrm{GFI}=0.92, \mathrm{RMSEA}=0.08$, $\mathrm{SRMR}=0.06, \mathrm{CFI}=0.96, \mathrm{IFI}=0.94, \mathrm{NFI}=0.96$, and all models have satisfactory values on fit indices. The factor loading of all items ranged from 0.66 to 0.95 , and all composite reliability ranged from 0.60 to 0.72 , suggesting that the observed variables sufficiently represented the latent variables.

Data Analysis Data analysis was conducted with SPSS statistics package version 22.0; SPSS Inc., Chicago, IL. Statistical significance was regarded as $p<0.05$. Pearson's correlation was conducted to examine the relationships between mindfulness, basic needs, subjective vitality, and burnout. A bootstrapping approach was used to test the mediating effect of basic psychological needs on mindfulness in predicting subjective vitality and athlete burnout.

\section{Results}

\section{Descriptive Statistics and Bivariate Correlations of Variables}

The means, standard deviations, and bivariate correlations for all variables are presented in Table 1 . The mean mindfulness 
Table 1 Descriptive statistics and bivariate correlations of variables

\begin{tabular}{lllllll}
\hline & (A) & (B) & (C) & (D) & (E) & (F) \\
\hline (A) Mindfulness & 1.00 & $0.52^{*}$ & $0.62^{*}$ & $0.42^{*}$ & $0.43^{*}$ & $-0.50^{*}$ \\
(B) Autonomy & & 1.00 & $0.23^{*}$ & $0.26^{*}$ & $0.46^{*}$ & $-0.30^{*}$ \\
(C) Competence & & & 1.00 & $0.51^{*}$ & $0.29^{*}$ & $-0.52^{*}$ \\
(D) Relatedness & & & & 1.00 & $0.37^{*}$ & $-0.49^{*}$ \\
(E) Subjective vitality & & & & & 1.00 & $-0.30^{*}$ \\
(F) Burnout & & & & & & 1.00 \\
Mean & 3.23 & 5.69 & 4.41 & 5.44 & 5.53 & 2.43 \\
SD & 0.46 & 1.01 & 1.56 & 1.43 & 1.01 & 0.91 \\
\hline
\end{tabular}

$N=120 . *$ indicates $p<0.05$

score was relatively high, suggesting that golfers had a high average level of mindfulness. The mean basic psychological needs satisfaction variable score was above the scale's midpoint, suggesting that the golfers' basic psychological needs were satisfied. The subjective vitality mean score was relatively high, suggesting that the golfers had high average levels of subjective vitality. Finally, the mean score for burnout was below the midpoint of the response scale indicating that, on average, the golfers in this study had low levels of burnout.

The results indicated that autonomy $(\mathrm{r}=0.52 ; p<0.05)$, competence $(\mathrm{r}=0.62 ; p<0.05)$, relatedness $(\mathrm{r}=0.42$; $p<0.05)$, and subjective vitality $(\mathrm{r}=0.43 ; p<0.05)$ were positively related to mindfulness. Burnout $(\mathrm{r}=-0.50 ; p<0.05)$ was negatively related to mindfulness. On the other hand, autonomy $(\mathrm{r}=-0.30 ; p<0.05)$, competence $(\mathrm{r}=-0.52$; $p<0.05)$, relatedness $(\mathrm{r}=-0.49 ; p<0.05)$, and subjective vitality $(\mathrm{r}=0.43 ; p<0.05)$ were negatively related to burnout (Table 1)

\section{The Mediating Effect of Basic Psychological Needs on Mindfulness in Predicting Subjective Vitality}

During the bootstrapping analysis in the current study, the data were re-sampled five thousand times to calculate the indirect effect of each sample, as previously described (Preacher and Hayes 2004; 2008). The resulting output contains the mean indirect effect point estimate, standard error, and biascorrected (BC) $95 \%$ confidence interval (CI) for the indirect effect, as well as unstandardized path coefficients for all paths in the mediation model. The BC 95\% CI is considered to be the index relating to the significance of the indirect effect. Accordingly, when the BC 95\% CI does not cross zero, then it can be concluded that the indirect effect is statistically significant at $p<0.05$ (Preacher and Hayes 2004; 2008; Shrout \& Bolger, 2002).

In testing the mediation effects, first, the relationship between the independent variable and the proposed mediator was tested. The regression results show that mindfulness wesed positive relatedly to autonomy $(\beta=0.52, p<.05)$, competence $(\beta=0.62, p<.05)$, and relatedness $(\beta=0.42, p<.05)$. Second, the relationship between the proposed mediator and the dependent variable was tested. The regression results shows autonomy $(\beta=0.46, p<.05)$, competence $(\beta=0.29$, $p<.05)$, relatedness $(\beta=0.37, p<.05)$ related positively with subjective vitality. Finally, the relationship between the independent variable and dependent variable was tested without (Step 1) and with (Step 2) the mediator. The regression analysis in Step 1 revealed that mindfulness was positively related to subjective vitality $(\beta=0.43, p<.05)$. When autonomy and relatedness were entered into the regression, respectively, the regression coefficient for mindfulness decreased in Step 2 and was still significant $(\beta=0.26, p<.05 ; \beta=0.33, p<.05)$ but did not significantly account for competence $(\beta=0.05$, $p=.66$ ). Figure 1 represents the regression results embedded in the conceptual diagram. Table 2 indicates the results for basic psychological needs as the mediating variables between mindfulness and subjective vitality. The indirect and direct effects of autonomy (95\% CI 0.07 to 0.31 ) and relatedness ( $95 \%$ CI 0.00 to 0.21 ) were significant between mindfulness and subjective vitality, suggesting complementary (partial) mediation. Autonomy and relatedness was found to be the indirect mediator in the relationship between mindfulness and subjective vitality.

\section{The Mediating Effect of Basic Psychological Needs on Mindfulness in Predicting Burnout}

In testing the mediation effects, first, the relationship between the independent variable and the proposed mediator was tested. The regression results show that mindfulness wesed positive relatedly to autonomy ( $\beta=0.52, p<.05)$, competence $(\beta=0.62, p<.05)$, and relatedness $(\beta=0.42, p<.05)$. Second, the relationship between the proposed mediator and the dependent variable was tested. The regression results show that autonomy $(\beta=-0.30, p<.05)$, competence $(\beta=-0.52$, $p<.05)$, and relatedness $(\beta=-0.49, p<.05)$ related negatively with burnout. Finally, the relationship between the independent variable and dependent variable was tested without (Step 1) and with (Step 2) the mediator. The regression analysis in Step 1 revealed that mindfulness was negatively related to burnout $(\beta=-0.50, p<.05)$. When competence and relatedness entered into the regression, respectively, the regression coefficient for mindfulness decreased in Step 2 and was still significant $(\beta=-0.29, p<.05 ; \beta=-0.35, p<.05)$ but did not significantly account for autonomy $(\beta=-0.06, p=.56)$. Figure 2 represents the regression results embedded in the conceptual diagram. Table 3 demonstrates the results for basic psychological needs as the mediating variables between mindfulness and burnout. The indirect and direct effect of competence $(95 \% \mathrm{CI}-0.38$ to -0.08$)$ and relatedness $(95 \%$ CI -0.26 to -0.06 ) was significant between mindfulness and burnout, 
Fig. 1 Mediating role of autonomy and relatedness in the relationship between mindfulness and subjective vitality

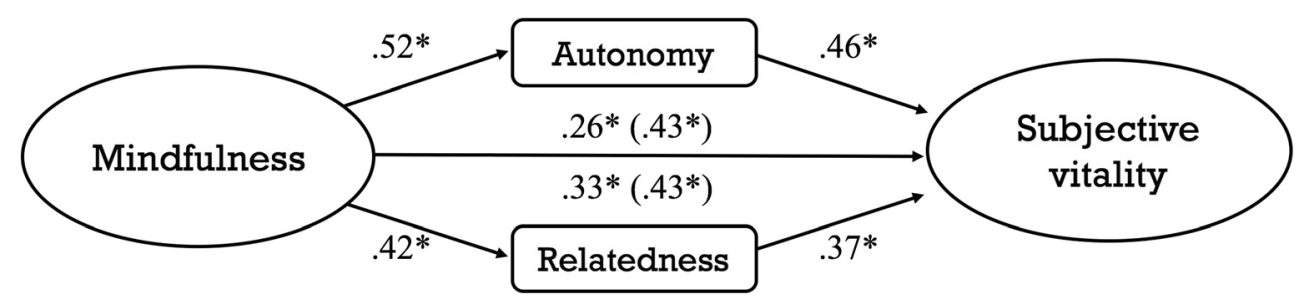

suggesting complementary (partial) mediation. Competence and relatedness was found to be the indirect mediator in the relationship between mindfulness and $\mathrm{s}$ burnout.

\section{Discussion}

In this study, we aimed to examine the mediating effect of basic psychological needs on mindfulness in predicting subjective vitality and burnout in athletes. Our findings indicate the significance of mindfulness for success from the perspective of professional golf athletes and supports our hypothesis.

We found that the association between mindfulness and subjective vitality were partially mediated by autonomy and relatedness, and indicated that mindfulness could further enhance golfer's subjective vitality through fulfillment of autonomy and relatedness. This finding is consistent with the results of Chang et al. (2015), who found that mindfulness could further enhance university students' well-being through the satisfaction of through the satisfaction of the same three basic psychological needs investigated in the current study. However, no mediating effects were recorded between competence and golfers' mindfulness and subjective vitality. This result is consistent with Ryan et al. (2010), who found that competence was not a mediator between working time and subjective vitality amongst employees in different occupations. Rather, they concluded that the competence of workers was affected by the duration of their work experience. Golfing is a sport that requires high skill, and thus to become highly competent, athletes must have a high degree of vitality to challenge themselves and improve their golf skills. This may explain why competence was not found to be a mediator between mindfulness and subjective vitality. Therefore, satisfactory autonomy and relatedness in golfers play important mediating roles in mindfulness and subjective vitality. Promoting mindfulness to satisfy golfers' need of autonomy and relatedness may enhance subjective vitality. This finding has important implications, since it highlights that mindfulness may affect golfers' autonomy and relatedness, thus enhancing subjective vitality through satisfaction of different psychological needs.

Moreover, we found that the association between mindfulness and burnout was partially mediated by the needs of competence and relatedness. Indeed, this finding indicated that mindfulness could further reduce golfer's burnout through the fulfillment of competence and relatedness needs. This is consistent with the work of Quested and Duda (2011), which found that basic psychological needs (i. e., autonomy, competence, and relatedness) are mediators between autonomy support and burnout. The authors suggested that when the three basic psychological needs are fulfilled, perceived burnout may be reduced. On the contrary, no mediating effects were recorded between autonomy and golfers' mindfulness on burnout in the current study. As golf is an individual sport, golfers have high autonomy to choose when and what they want to practice. This may be the reason why autonomy was not a mediating factor between mindfulness and burnout. Therefore, the satisfaction of golfers' competence and relatedness play an important mediating role in mindfulness and burnout. Promoting mindfulness to satisfy golfers' need for competence and relatedness may reduce burnout.

\section{Implications}

This study examined the mediating effect of basic psychological needs on mindfulness to predict subjective vitality and

Table 2 Bootstrap analysis summary of basic psychological needs as mediating variables between mindfulness and subjective vitality

\begin{tabular}{|c|c|c|c|c|c|c|}
\hline IV & MV & DV & $\begin{array}{l}\text { a path } \\
\text { coefficient (IV-MV) }\end{array}$ & $\begin{array}{l}\text { b path } \\
\text { coefficient (MV-DV) }\end{array}$ & $\begin{array}{l}\text { c path coefficient } \\
\text { (direct effect) }\end{array}$ & $\begin{array}{l}\text { BC 95\% CI mean } \\
\text { indirect effect } \\
\text { (lower and upper) }\end{array}$ \\
\hline Mindfulness & Autonomy & Subjective vitality & $0.51 *$ & $0.32 *$ & $0.25^{*}$ & $0.07 \sim 0.31^{*}$ \\
\hline Mindfulness & Competence & Subjective vitality & $0.61 *$ & 0.05 & $0.38^{*}$ & $-0.11 \sim 0.15$ \\
\hline Mindfulness & Relatedness & Subjective vitality & $0.40 *$ & $0.24 *$ & $0.32 *$ & $0.00 \sim 0.21^{*}$ \\
\hline
\end{tabular}

$N=120 . * p<0.05$

$\mathrm{IV}$, independent variable; MV, mediating variable; DV, dependent variable; BC 95\% CI, bias-corrected 95\% confidence interval 
Fig. 2 Mediating role of competence and relatedness in the relationship between mindfulness and burnout

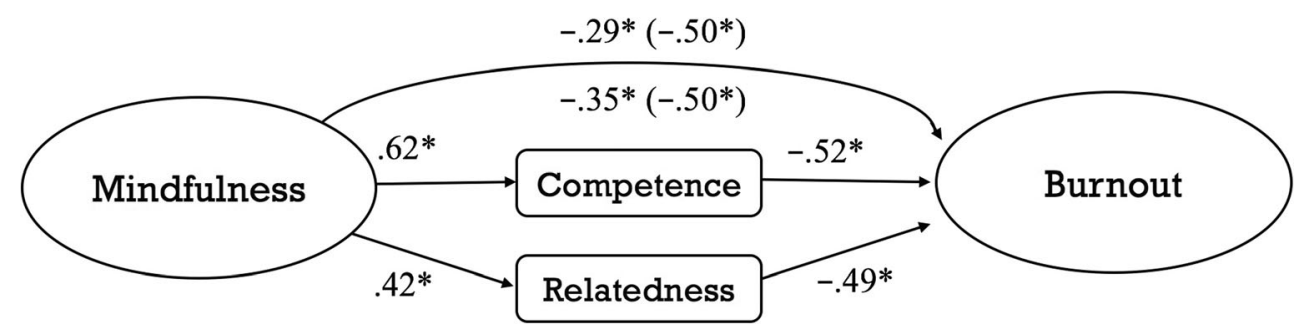

athlete burnout in professional golfers. The focus was on the mindfulness concept as well as possible mechanisms of impact. The findings of the current study revealed that basic psychological needs have a meaningful correlation with mindfulness and subjective vitality and burnout. The basic psychological needs take an important place in this association. The relationship between mindfulness and subjective vitality and burnout was mediated partially by basic psychological needs, which are the principal source of subjective vitality according to the SDT perspective. According to SDT, mindfulness is regarded as an essential element for individuals to actively explore the internal and external worlds to satisfy their psychological needs (Ryan \& Deci, 2017). SDT utilizes awareness processes during mindfulness training to satisfy individuals' psychological needs through each of the awareness processes and cultivate satisfaction with psychological needs or to address the thwarting of psychological needs. Overall, the use of mindfulness in sports seems to be a promising approach. By explaining what and how performance-related skills can be improved with mindfulness practice, the theoretical considerations show that it makes sense to scientifically study this approach, let alone its value as a practical (Pineau et al., 2014). Mindfulness seems to be a holistic concept that fosters the development of several personal, sport, and performance-relevant psychological skills (Gross et al., 2018; Josefsson et al., 2019). Thus, mindfulness practice can be taught in many ways. Formal mindfulness breathing exercises might be introduced in a non-sports setting. To explain the mindfulness philosophy, using the athlete's own examples and demonstrating a non-judging and accepting attitude in his or her specific situation is important. For example, a body scan exercise can easily be administered during the cool-down phase at the end of a training session. At first glance, mindfulness seems incompatible with a professional golfer's perspective sports setting. However, with appropriate openness and sport-specific expertise, mindfulness techniques can be integrated into a sports setting in many ways.

\section{Limitations and Future Research}

This study has several limitations. First, we obtained data from a convenience sample of Taiwanese professional golfers. Thus, the findings from this study cannot be generalized to other types of sport or to the general population. Second, although this study examined the roles of different behavioral correlates of the basic psychological needs while accounting for demographic factors, we could not rule out other potential individual determinants (e.g., golfers' personality or years of prior training), or environmental determinants (e.g., neighborhood training environment) that might influence golfers' experiences and changes on basic psychological needs fulfillment. Third, this study focused on golfers' mental health variables, such as subjective vitality, burnout, and psychological needs satisfaction, which did not consider variables related to golfers' performance variables; therefore, their influence on golfers' performance cannot be determined. Fourth, this study is a correlation study, so its clinical significance did not explain enough. Future research should involve intervention studies, where the effect of mindfulness training on golfers' basic psychological needs, subjective vitality, and burnout is examined through an experimental design to manipulate mindfulness and explain its influence on golfers' psychological processes. Finally, the basic psychological needs should be

Table 3 Bootstrap analysis summary for basic psychological needs as mediating variables between mindfulness and burnout

\begin{tabular}{lllllll}
\hline IV & MV & DV & $\begin{array}{l}\text { a path } \\
\text { coefficient (IV-MV) }\end{array}$ & $\begin{array}{l}\text { b path } \\
\text { coefficient (MV-DV) }\end{array}$ & $\begin{array}{l}\text { c path coefficient } \\
\text { (direct effect) }\end{array}$ & $\begin{array}{l}\text { BC 95\% CI mean } \\
\text { indirect effect } \\
\text { (lower and upper) }\end{array}$ \\
\hline Mindfulness & Autonomy & Burnout & $0.51^{*}$ & -0.06 & $-0.47^{*}$ & $-0.14 \sim-0.09$ \\
Mindfulness & Competence & Burnout & $0.61^{*}$ & $-0.34^{*}$ & $-0.29^{*}$ & $-0.38 \sim-0.08^{*}$ \\
Mindfulness & Relatedness & Burnout & $0.40^{*}$ & $-0.35^{*}$ & $-0.35^{*}$ & $-0.26 \sim-0.06^{*}$ \\
\hline
\end{tabular}

$N=120 . * p<0.05$

$\mathrm{IV}$, independent variable; MV, mediating variable; DV, dependent variable; BC 95\% CI, bias-corrected 95\% confidence interval 
measured more frequently and over a longer period of time to fully assess the dynamic nature of change in mindfulness.

\section{Conclusion}

The purpose of this study was to examine the mediating effect of the basic psychological needs on mindfulness to predict subjective vitality and athlete burnout. Additionally, the study identified key mindfulness correlates of the observed change on basic psychological needs fulfillment. Our findings suggest that mindfulness changes over time, and that this change varies by individual as well as the specific facet being measured. Furthermore, the degree of change is not uniform, as it is influenced by basic psychological needs fulfillment correlates, such as the fulfillment of autonomy and relatedness. Understanding the dynamics of the basic psychological needs change over time is important when attempting to maintain mindfulness during sport performance.

Acknowledgements This study was supported by the National Taiwan Normal University, Taiwan.

Funding This study was funded by a direct research grant from the National Taiwan Normal University.

Data Availability The datasets analyzed during the current study are available from the corresponding author on reasonable request.

\section{Declarations}

Conflict of Interest All authors declare no conflict of interest.

\section{References}

Adie, J. W., Duda, J. L., \& Ntoumanis, N. (2008). Autonomy support, basic need satisfaction and the optimal functioning of adult male and female sport participants: A test of basic needs theory. Motivation and Emotion, 32, 189-199. https://doi.org/10.1007/s11031-0089095-z.

Adie, J. W., Duda, J. L., \& Ntoumanis, N. (2010). Achievement goals, competition appraisals, and the well-and ill-being of elite youth soccer players over two competitive seasons. Journal of Sport and Exercise Psychology, 32(4), 555-579. https://doi.org/10.1123/jsep. 32.4.555.

Adie, J. W., Duda, J. L., \& Ntoumanis, N. (2012). Perceived coachautonomy support, basic need satisfaction and the well-and ill-being of elite youth soccer players: A longitudinal investigation. Psychology of Sport and Exercise, 13(1), 51-59. https://doi.org/10. 1016/j.psychsport.2011.07.008.

Baer, R. A., Smith, G. T., Hopkins, J., Krietemeyer, J., \& Toney, L. (2006). Using self-report assessment methods to explore facets of mindfulness. Assessment, 13(1), 27-45. https://doi.org/10.1177/ 1073191105283504.
Bagozzi, R. P., \& Yi, Y. (1988). On the evaluation of structural equation models. Journal of the Academy of Marketing Science, 16(1), 74 94. https://doi.org/10.1007/BF02723327.

Bahrami, Z., \& Cranney, J. (2018). Integrated conative model of wellbeing: From motives to well-being. Journal of Happiness Studies, 19(4), 961-981. https://doi.org/10.1007/s10902-017-9845-2.

Brown, K. W., \& Ryan, R. M. (2003). The benefits of being present: Mindfulness and its role in psychological well-being. Journal of Personality and Social Psychology, 84(4), 822-848. https://doi. org/10.1037/0022-3514.84.4.822.

Brown, K. W., \& Ryan, R. M. (2004). Perils and promise in defining and measuring mindfulness: Observations from experience. Clinical Psychology: Science and Practice, 11(3), 242-248. https://doi.org/ 10.1093/clipsy.bph078.

Cathcart, S., McGregor, M., \& Groundwater, E. (2014). Mindfulness and flow in elite athletes. Journal of Clinical Sport Psychology, 8(2), 119-141. https://doi.org/10.1123/jcsp.2014-0018.

Chang, J. H., Huang, C. L., \& Lin, Y. C. (2015). Mindfulness, basic psychological needs fulfillment, and well-being. Journal of Happiness Studies, 16(5), 1149-1162. https://doi.org/10.1007/ s10902-014-9551-2.

Chang, W. H., Chang, J. H., \& Chen, L. H. (2018). Mindfulness enhances change in athletes' well-being: The mediating role of basic psychological needs fulfillment. Mindfulness, 9(3), 815-823. https://doi. org/10.1007/s12671-017-0821-z.

Chuang, H. Y., \& Chi, L. K. (2017). The relationship between mindfulness and golf putting performance. Sports Coaching Science, 45, 55-66. https://doi.org/10.6194/SCS.2017.45.06.

Deci, E. L., \& Ryan, R. M. (2000). The" what" and" why" of goal pursuits: Human needs and the self-determination of behavior. Psychological Inquiry, 11(4), 227-268. https://doi.org/10.1207/ S15327965PLI1104 01.

Deci, E. L., Ryan, R. M., Gagné, M., Leone, D. R., Usunov, J., \& Kornazheva, B. P. (2001). Need satisfaction, motivation, and wellbeing in the work organizations of a former eastern bloc country: A cross-cultural study of self-determination. Personality and Social Psychology Bulletin, 27(8), 930-942. https://doi.org/10.1177/ 0146167201278002 .

Fraser-Thomas, J., Côté, J., \& Deakin, J. (2008). Understanding dropout and prolonged engagement in adolescent competitive sport. Psychology of Sport and Exercise, 9(5), 645-662. https://doi.org/ 10.1016/j.psychsport.2007.08.003.

Gooding, A., \& Gardner, F. L. (2009). An investigation of the relationship between mindfulness, preshot routine, and basketball free throw percentage. Journal of Clinical Sport Psychology, 4, 303319. https://doi.org/10.1123/jcsp.3.4.303.

Götmann, A., \& Bechtoldt, M. N. (2021). Coping with COVID-19-longitudinal analysis of coping strategies and the role of trait mindfulness in mental well-being. Personality and Individual Differences, 175, 110695. https://doi.org/10.1016/j.paid.2021.110695.

Gross, M., Moore, Z. E., Gardner, F. L., Wolanin, A. T., Pess, R., \& Marks, D. R. (2018). An empirical examination comparing the mindfulness-acceptance-commitment approach and psychological skills training for the mental health and sport performance of female student athletes. International Journal of Sport and Exercise Psychology, 16(4), 431-451. https://doi.org/10.1080/1612197X. 2016.1250802.

Hodge, K., Lonsdale, C., \& Ng, J. Y. Y. (2008). Burnout in elite rugby: Relationships with basic psychological needs fulfilment. Journal of Sports Sciences, 26, 835-844. https://doi.org/10.1080/ 02640410701784525.

Hu, L., \& Bentler, P. M. (1999). Cutoff criteria for fit indexes in covariance structure analysis: Conventional criteria versus new alternatives. Structural Equation Modeling, 6, 1-55. https://doi.org/10. 1080/10705519909540118. 
Josefsson, T., Ivarsson, A., Gustafsson, H., Stenling, A., Lindwall, M., Tornberg, R., \& Böröy, J. (2019). Effects of mindfulnessacceptance-commitment (MAC) on sport-specific dispositional mindfulness, emotion regulation, and self-rated athletic performance in a multiple-sport population: An RCT study. Mindfulness, 10(8), 1518-1529. https://doi.org/10.1007/s12671-019-01098-7.

Kabat-Zinn, J. (2003). Mindfulness-based interventions in context: Past, present, and future. Clinical Psychology: Science and Practice, 10(2), 144-156. https://doi.org/10.1093/clipsy.bpg016.

Kanekar, A., \& Sharma, M. (2020). COVID-19 and mental well-being: Guidance on the application of behavioral and positive well-being strategies. Healthcare, 8(3), 336-342. https://doi.org/10.3390/ healthcare 8030336.

Lonsdale, C., Hodge, K., \& Rose, E. (2009). Athlete burnout in elite sport: A self-determination perspective. Journal of Sports Sciences, 27(8), 785-795. https://doi.org/10.1080/ 02640410902929366.

Mack, D. E., Wilson, P. M., Oster, K. G., Kowalski, K. C., Crocker, P. R. E., \& Sylvester, B. D. (2011). Well-being in volleyball players: Examining the contributions of independent and balanced psychological need satisfaction. Psychology of Sport and Exercise, 12, 533-539. https://doi.org/10.1016/j.psychsport.2011.05.006.

McCracken, L. M., \& Yang, S. Y. (2008). A contextual cognitivebehavioral analysis of rehabilitation workers' health and well-being: Influences of acceptance, mindfulness, and values-based action. Rehabilitation Psychology, 53(4), 479-485. https://doi.org/10. 1037/a0012854.

Perreault, S., Gaudreau, P., Lapointe, M.-C., \& Lacroix, C. (2007). Does it take three to tango? Psychological need satisfaction and athlete burnout. International Journal of Sport Psychology, 38, 437-450.

Pineau, T., Glass, C., \& Kaufman, K. (2014). Mindfulness in sport performance. In A. Ie, C. Ngnoumen, \& E. Langer (Eds.), Handbook of mindfulness (pp. 1004-1034). Wiley Blackwell. https://doi.org/10. 1002/9781118294895.ch52.

Preacher, K. J., \& Hayes, A. F. (2004). SPSS and SAS procedures for estimating indirect effects in simple mediation models. Behavior Research Methods, Instruments, \& Computers, 36(4), 717-731. https://doi.org/10.3758/BF03206553.

Prime, H., Wade, M., \& Browne, D. T. (2020). Risk and resilience in family well-being during the COVID-19 pandemic. American Psychologist, 75(5), 631-643. https://doi.org/10.1037/ amp0000660.

Quested, E., \& Duda, J. L. (2011). Antecedents of burnout among elite dancers: A longitudinal test of basic needs theory. Psychology of Sport and Exercise, 12(2), 159-167. https://doi.org/10.1016/j. psychsport.2010.09.003.

Raedeke, T. D., \& Smith, A. L. (2001). Development and preliminary validation of an athlete burnout measure. Journal of sport and exercise psychology, 23(4), 281-306 https://www.researchgate.net/ publication/232479391.
Roche, M., Haar, J. M., \& Luthans, F. (2014). The role of mindfulness and psychological capital on the well-being of leaders. Journal of Occupational Health Psychology, 19(4), 476-489 https:// digitalcommons.unl.edu/managementfacpub/126.

Ryan, R. M., \& Frederick, C. (1997). On energy, personality, and health: Subjective vitality as a dynamic reflection of well-being. Journal of Personality, 65(3), 529-565. https://doi.org/10.1111/j.1467-6494. 1997.tb00326.x.

Ryan, R. M., \& Deci, E. L. (2000). Self-determination theory and the facilitation of intrinsic motivation, social development, and wellbeing. American Psychologist, 55(1), 68-78.

Ryan, R. M., Bernstein, J. H., \& Brown, K. W. (2010). Weekends, work, and well-being: Psychological need satisfactions and day of the week effects on mood, vitality, and physical symptoms. Journal of Social and Clinical Psychology, 29(1), 95-122. https://doi.org/10. 1521/jscp.2010.29.1.95.

Ryan, R. M., \& Deci, E. L. (2017). Self-determination theory: Basic psychological needs in motivation, development, and wellness. Guilford Publications.

Ryff, C. D., Singer, B. H., \& Dienberg Love, G. (2004). Positive health: Connecting well-being with biology. Philosophical transactions of the Royal Society of London. Series B: Biological Sciences, 359(1449), 1383-1394. https://doi.org/10.1098/rstb.2004.1521.

Scott-Hamilton, J., Schutte, N. S., \& Brown, R. F. (2016). Effects of a mindfulness intervention on sports-anxiety, pessimism, and flow in competitive cyclists. Applied Psychology: Health and Well-Being, 8(1), 85-103. https://doi.org/10.1111/aphw.12063.

Shankland, R., Tessier, D., Strub, L., Gauchet, A., \& Baeyens, C. (2021). Improving mental health and well-being through informal mindfulness practices: An intervention study. Applied Psychology: Health and Well-Being, 13(1), 63-83. https://doi.org/10.1111/aphw.12216.

Shrout, P. E., \& Bolger, N. (2002). Mediation in experimental and nonexperimental studies: New procedures and recommendations. Psychological Methods, 7(4), 422-445. https://doi.org/10.1037/ 1082-989X.7.4.422.

Tanhan, A. (2019). Acceptance and commitment therapy with ecological systems theory: Addressing Muslim mental health issues and wellbeing. Journal of Positive School Psychology, 3(2), 197-219. https://doi.org/10.47602/jpsp.v3i2.172.

Tanhan, A. (2020). COVID-19 Sürecinde Online Seslifoto (OSF) Yöntemiyle Biyopsikososyal Manevi ve Ekonomik Meseleleri ve Genel İyi Oluş Düzeyini Ele Almak: OSF'nin Türkçeye Uyarlanmas1. Electronic Turkish Studies, 15(4), 1029-1086. https://doi.org/10.7827/TurkishStudies.44451.

Weinstein, N., \& Ryan, R. M. (2011). A self-determination theory approach to understanding stress incursion and responses. Stress and Health, 27(1), 4-17. https://doi.org/10.1002/smi.1368.

Publisher's note Springer Nature remains neutral with regard to jurisdictional claims in published maps and institutional affiliations. 